\title{
«Les branques entrellaçades»: un motiu del folklore verbal i els gèneres mixtos
}

\author{
Joan A. Argenter i Giralt \\ Universitat Autònoma de Barcelona \\ joan.argenter@uab.cat
}

\begin{abstract}
RESUM
L'article aborda comparativament un motiu de l'art verbal $i$ alhora la seva interacció amb un problema general de l'estudi del folklore: el dels gèneres mixtos i llur significació. El motiu en qüestió és designat «Twining branches» (E63I.o.I) en l'índex de Thompson. S'assenyala l'eventual precedent clàssic ovidià $i$ se'n considera la presència en romanços de la tradició romànica peninsular i en balades angloamericanes, gèneres versificats. Si comparteixen el motiu de les branques entrellaçades, difereixen en aspectes funcionals i argumentals. S'aporta una narració oral beduïna del desert Líbic que conté l'argument i el motiu. Aquest text oral és un gènere mixt: hi coexisteixen prosa $i$ vers (prosimetrum). S'analitzen diferències funcionals respecte als textos anteriors i se'n vincula l'especificitat a la naturalesa de l'ordre social en la societat beduïna, a la ideologia que hi és hegemònica, a la identitat ètnica i a la cultura verbal beduïna arabitzada. S'interpreta el gènere mixt en funció de conceptes desenvolupats a partir de la poètica jakobsoniana $i$, sobretot, en funció del context en què es produeix, això és, de l'especificitat històrica i d'una interpretació èmica, la qual ens permet accedir a la significació que vehicula la juxtaposició de prosa $i$ vers en un context d'actuació específic.
\end{abstract}

PARAULES CLAU

«Twining branches»; romanços iberoromànics; balades angloamericanes i una narració beduïna; prosimetrum; interpretació èmica

Estudis de Literatura Oral Popular, núm. 4, 2OI5, II-32 | DOI: Io.I7345/elop2OI5II-32 ISSN: 20I4-7996 | http://revistes.urv.cat/index.php/elop 


\begin{abstract}
This article takes a comparative approach to a verbal art motif, the Twining Branches (E63I.o.I in Thompson's index), and its relationship with a general problem in the study of folklore: mixed genres and their meaning. The article highlights a classical Ovidian precedent and considers the presence of the motif in romances from the Romance language traditions of the Iberian Peninsula and in Anglo-American ballads, both of these being versified genres. Despite being shared by both genres, the use of the Twining Branches motif in each one differs in terms of its function and deployment as a plot device. The article also presents an oral mixed-genre (prosimetrum) Bedouin narrative from the Libyan Desert containing the same plot and motif. Functional differences between this and the former versified genres are discussed and it is shown that the specificity of the Bedouin version stems from the social order and ideological values dominant in Bedouin society, its members' ethnic identity, and the Arabized Bedouin oral culture. The mixed genre is interpreted in relation to Jakobson's concepts regarding poetics and linguistics and, above all, to the context in which it is produced, that is, its historical specificity and its emic interpretation. The findings reveal the cultural meaning behind the juxtaposition of prose and verse in a particular performance context.
\end{abstract}

\title{
KEYWORDS
}

Twining branches motif; Iberian Romance songs; Anglo-American ballads; Bedouin narrative; prosimetrum; emic interpretation

REBUT: II.04.2OI4 | ACCEPTAT: 07.05.2OI4 


\section{Les branques entrellaçades:}

\section{un motiu present en diverses tradicions orals}

L'objectiu d'aquest article és abordar comparativament un motiu definit i catalogat de l'art verbal i alhora la seva interacció amb un problema general de l'estudi del folklore - i d'altres disciplines_ com és el dels gèneres mixtos i llur significació. ${ }^{\mathrm{I}}$

El motiu en qüestió és el que apareix com a E63I.o.I en l'índex de Thompson (I966) i com a tipus 970 amb la designació The Twining Branches en la tipologia d'Aarne-Thompson-Uther (Uther 2004) i a Oriol-Pujol (2003: 238). ${ }^{2}$

Aquest motiu té com un dels orígens remots, almenys en l'àmbit dels nostres referents culturals, el mite de Baucis i Filemon, cantat per Ovidi a les Metamorfosis (VIII: 6II-724), ${ }^{3}$ el qual encadena una sèrie de motius que ara no podem reproduir, alguns dels quals reapareixen en certes tradicions de romanços peninsulars i en llegendes èuscars. ${ }^{4}$

A banda d'aquest precedent, i descartada la tradició èuscar, el meu coneixement inicial de les composicions que inclouen el motiu que tractem es limitava, doncs, a les literatures tradicionals peninsulars romàniques i també a l'anglòfona, present en totes en romanços i balades, és a dir, en textos versificats. Les composicions en qüestió apareixen in extenso en els annexos. ${ }^{5}$ En el cos de l'article ens limitem a la citació del motiu esmentat i d'altres fragments necessaris per al fil de l'argument.

Aquests són els versos de la versió galaicoportuguesa, que hem extret de l'antologia poètica del portuguès Eugénio de Andrade.

De um nascera um cipreste,

E do outro um laranjal,

Um crescia, outro crescia,

Coas pontas se iam beijar.

El-rei, apenas tal soube,

I. Agraeixo l'oportunitat que em dóna Estudis de Literatura Oral Popular de contribuir a l'homenatge a un col-lega i amic, malgrat que jo no sigui un professional de la disciplina. Haig d'agrair l'ajut, els comentaris o els suggeriments de Lila Abu-Lughod, Jabier Kaltzakorta, Carme Oriol, Joan Miralles i les encertades admonicions de Lluís Polanco.

2. Oriol-Pujol l'anostren com «Els rosers entrellaçats», alhora que mantenen la referència a la denominació en anglès. Ara, per bé que moltes versions ens parlen de «rosers» (així en castellà o en anglès), d'altres són menys específiques o més adaptades a l'entorn, com veurem més avall.

3. Remetem a la versió bilingüe, traduïda en prosa, de la Fundació Bernat Metge (I930) i a la més recent traducció en vers, amb text monolingüe, de Jordi Perramon a Quaderns Crema (I996).

4. Agraeixo la informació de J. Kaltzakorta, les anotacions inacabades i el material inèdit del qual m’ha estat permès consultar. Catalán (I970: I89-I93) fa esment de diverses variants d'una cançó suletina que tracta el tema del romanç català «El mort i l'enamorada» (cast. «La enamorada de un muerto»). Tot i que s'hi poden rastrejar elements indubtables del mite ovidià, no contenen el motiu de les branques entrellaçades.

5. Entre les peninsulars, donem compte de versions galaicoportugueses, castellanes i catalana potser textualment elaborades. El motiu es retroba en aplecs del folklore castellà dels EUA i sefardita. 
Logo os mandara cortar.

Um deitava sangue vivo,

O outro sangue real;

De um nascera uma pomba,

De outro um pombo torcaz.

[...]

- «Mal haja tanto querer,

E mal haja tanto amar!

Nem na vida nem na morte

Nunca os pude separar.»

«Conde Nilo» de Andrade (I999: 53-55).

Ramón Menéndez Pidal (I948) dóna dues versions castellanes, la de «Conde Niño» i la de «Conde Nilo», que pràcticament coincideixen en la formulació del motiu que estudiem. ${ }^{6}$ En donem la primera:

De ella nació un rosal blanco,

de él nació un espino albar;

crece el uno, crece el otro,

los dos se van a juntar;

las ramitas que se alcanzan

fuertes abrazos se dan,

y las que no se alcanzaban

no dejan de suspirar.

La reina, llena de envidia,

ambos los mandó cortar;

el galán que los cortaba

no cesaba de llorar;

della naciera una garza,

dél un fuerte gavilán

juntos vuelan por el cielo,

juntos vuelan a la par.

«Romance del Conde Niño». Menéndez Pidal (I948: I3O-I3I).

Aquest romanç fou musicat i difós pel cantautor segovià Ismael Peña (I963) en un disc publicat i premiat a París, per bé que mai no s'edità a Espanya.

Les diverses versions castellanes i galaicoportugueses són molt pròximes, com ho és també la catalana, per bé que se'n separa en alguns aspectes: així, en aquesta

6. Amb encert Menéndez Pidal intitulà «Amor más poderoso que la muerte» aquestes diverses composicions, les varietats de les quals inclouen sempre -o quasi sempre (vegeu el cas català) - el motiu de les branques entrellaçades. La composició catalana solament conté el motiu següent en els romanços castellans: la transformació del trop vegetal en l'ornitològic o la sola presència d'aquest darrer. 
no és un conflicte entre pare o mare reials i filla, sinó entre marit i muller esposats en segones noces, malgrat una antiga promesa d'amor i d'espera a un primer marit destinat a galeres. El fet es produeix al seu retorn, en assabentar-se ell que el matrimoni és tot just consumat o a punt de consumar-se (Oriol-Pujol 2003: 238). A més, pròpiament no apareix el motiu de les branques entrellaçades, però sí la seva derivació ornitològica:

Lo primer cant que li feia

«Desperteu-vos, vida mia, sentireu cant de serena «Això no és cant de serena sinó que és lo meu marit «Si és veritat, vida mia, «i mateu lo meu marit La un mor a mitja nit, l'altar de Santa Maria de l'un surt una coloma son marit se despertà:

si voleu sentir cantar, o peix que roda pel mar.» o peix que roda pel mar, lo que me vàreu quitar.» prompte l'aniré a matar.» per mi podeu començar.» l'altre al despuntar el clar, los dos varen enterrar; i de l'altre un colomar.

«Don Lluís de Montalbà». Romancer Català — text establert per Manuel Milà i Fontanals-, MOLC (I980: 87).

Una altra tradició de què tenim coneixença és l'anglosaxona, concretament la que ens ha arribat a través dels cantants de folk-song que a partir dels anys seixanta es dedicaren a aplegar la tradició de balades i cançons populars als EUA. És molt probable que la composició a què ens referim tingui l'origen en una balada escocesa. Versions amb variants foren recollides per Art Garfunkel i Pete Seeger, i cantades per tots dos i per Joan Baez:

They buried Willy in the old church yard and Barbara in the new one, And from William's grave, there grew a rose, from Barbara's, a green briar.

They grew and grew in the old church yard,

Till they could grow no higher, And there they tied in a true lover's knot, The red rose and the briar.

«Barbara Allen», balada. Versió d'Art Garfunkel (I973). ${ }^{7}$

Comprovem, doncs, que aquest motiu -o un seu derivat en el cas catalàapareix en totes quatre llengües i tradicions poètiques en balades i romanços, composicions en vers per definició. ${ }^{8}$

7. Sorprenentment, la versió de Seeger (2003 [1958]) omet la darrera estrofa, la que conté el motiu de les branques entrellaçades. Quant a l'origen escocès de la balada «The Douglas Tragedy», vegeu la localització precisa que en fa Child (I857: II 4-I2O). Els versos pertinents: «Out o' the lady's grave grew a bony red rose / And out o' the knight's a brier / And they twa met, and they twa plat / And fain they wad be near / And a' the warld ken right weel, / They were twa lovers dear» (I857: II9).

8. Carme Oriol em crida l'atenció - i li ho agraeixo- sobre la narració del senyor Frederic Martí, de Torelló, inclosa per Amades (I950: I380), en la qual apareix el motiu que ens ocu- 
Albert Hauf (20Io) estudia «Les transformacions»,9 una mena de romanç encadenat el tema del qual és un seguit de metamorfosis recíproques entre pretendent i pretesa amb l'objectiu de no perdre's de petja — fugint i aproximant-se metonímicament. Però no hi apareix el motiu de les branques entrellaçades que s'enfilen cel amunt. ${ }^{\text {Io }}$

En aquest mateix capítol, Hauf (20IO: 338-34I) tracta, amb menys detall, del tema de «l'Amor més fort que la mort», en expressió anostrada de la de Menéndez Pidal, i es refereix a diverses variacions del nostre romanç, amb el motiu, efectivament, de les branques entrellaçades. Curiosament, però, també hi retreu versions portugueses i castellanes i fins i tot aporta una citació de la balada escocesa que és a l'origen, com hem suggerit, de l'aplegada per Garfunkel (I973) i Seeger (2003 [I958]) - i cap de catalana. Tot plegat és un indici indirecte o fa pensar que el motiu no es troba en la cançó lírica catalana, si no és la "plausibilitat» a què ens hem referit en la nota 8 - en canvi, hi trobem el seu derivat ornitològic.

En la composició ovidiana a la qual ens hem referit, el motiu se centra en la transformació simultània dels amorosos i ancians esposos en arbres o tiges que finalment neixen d'un sol tronc, és a dir, que resten units per l'arrel un cop morts. És l'acompanyament en l'estimació fins al darrer moment i l'amor que roman més enllà d'aquest moment i de la mort, la victòria de l'amor sobre la mort. El motiu apareix, un cop més, en un text versificat.

\section{Una narració beduïna i els gèneres mixtos}

Segons Thompson (I966), el motiu es retroba en diverses tradicions del folklore del món, ben allunyades entre elles. Existeix una tradició beduïna d'aquest motiu inclosa en una narració en prosa, en la qual, però, apareixen fragments versificats. L'existència d'aquesta mena de gènere mixt és prou coneguda i Joseph Harris i Karl Reichl (I997) n'han aplegat estudis exemplars sobre les més diverses tradicions d'arreu i de tot temps. ${ }^{\text {II }}$ Probablement amb variants i amb matisos, aquesta mena de forma mixta ha estat designada en la tradició occidental amb el terme prosimetrum - 'prosa+vers' - (Dronke I994). ${ }^{12}$ En termes conceptuals, per exemple, hi ha qui distingeix prosimetrum i versiprosa, segons que la dominant (Jakobson I98I [i935]) de la tradició i de la composició sigui la narració en vers amb elements en prosa intercalats o que la dominant de la narració sigui la prosa i els versos hi

pa, reproduit de manera prou fidel. Plausiblement, l'origen d'aquest motiu devia trobar-se en alguna composició en vers. En tot cas, la meva afirmació continua essent certa.

9. El capítol de Hauf el reprodueix, comparativament amb altres versions europees; també es pot trobar a Bohigas (1983) i altres repertoris.

Io. L'estrofa 9 d'una versió castellana que dóna s'hi acosta, però no es pot considerar una variació del motiu: «Tú eres palma y yo soy dátil, / tú eres zarza y yo me enredo, / tú eres la rosa fragante / del jardín de mi recreo» (Hauf 20Io: 336). Aquesta estrofa de to líric defuig l'encadenament i el caràcter dinàmic de la resta d'estrofes. Tot i la similitud temàtica, sembla una interpolació.

II. Oriol (I997) reporta una «performance», recollida a la parròquia de Sant Julià de Lòria, que intercala versos en un relat en prosa i que interpreta com la «prosificació» d'un romanç. I2. El terme es pot datar des del segle XII i, doncs, la consciència del fenomen, sia entès com a gènere, al costat d'altres, sia com a característic de determinats gèneres. 
apareguin intercalats, ${ }^{\mathrm{I} 3}$ és a dir, segons quin sigui el terme «marcat» de la composició (Hanson i Kiparsky I997: 36). ${ }^{14}$ Altres autors, sobretot indoeuropeistes, aborden el problema des d'un punt de vista genètic (la prosa seria la forma primitiva de la narració, eventualment amb versos intercalats, sovint citacions o expressions emotives, i d'aquí deu haver derivat progressivament cap a la forma de la tirallonga de versos que coneixem dels poemes homèrics). En fi, els semitistes tracten la singularitat de la relació difusa poesia/prosa en les literatures orientals.

La narració beduïna fou aplegada per Lila Abu-Lughod de tribus establertes al desert Líbic d'Egipte, allí anomenat desert Occidental —una llenca de 500 quilòmetres que s'estén de l'oest del Caire fins a Líbia-, i reproduïda (Abu-Lughod I986: 249-250) en el seu interessant estudi etnogràfic sobre la construcció de l'ordre social i la complexitat cultural en la societat beduïna Awlad 'Ali, com són conegudes. En allò que aquí és pertinent, l'antropòloga hi detectà la coexistència d'un discurs hegemònic que vehicula la ideologia de l'honor i la modèstia com a valors morals públics constrenyedors, expressat en el «llenguatge ordinari», i un discurs alternatiu que vehicula els sentiments «impropis» de vulnerabilitat i d'amor, expressat mitjançant la recitació o el cant de composicions líriques, vinculades a un context determinat i anomenades ghinnāwa ('cançonetes'), en boca de dones o joves que altrament assumeixen els valors establerts, expressats en llenguatge comú en la vida quotidiana. És l'assumpció d'aquesta doble dimensió discursiva el que genera el sentiment d'ambivalència cultural que viuen les dones d'Alwad 'Ali i el que fa palesa la complexitat de llur identitat cultural i de la mateixa noció de «cultura». «Dir cantant allò que no es pot dir enraonant»: un fenomen cultural que no els n'és privatiu. Tanmateix, no es tracta pas d'un tabú verbal ni de conductes reprimides, ja que, potser de manera compensatòria, els beduïns -i en general els pobles àrabs - valoren l'expressió poètica, l'embelliment del llenguatge. El que fóra impropi és expressar aquells sentiments en el llenguatge ordinari de cada dia, i subvertir-ne els valors i el discurs. El control de l'expressió pública dels sentiments més íntims forma part de la cultura verbal i social dels pobles del desert (Abu-Lughod I986; Reynolds I997: 278) i, de fet, de la cultura aràbiga (Reynolds I997: 278; Scott Meisami I997). ${ }^{15}$

La «performance» de què tractarem, però, és tot un altre gènere que les cançonetes: una narració amb versos incrustats.

I3. «The 'dominant' may be defined as the focusing component of a work of art: it rules, determines, and transforms the remaining components. It is the dominant which guarantees the integrity of the structure» (Jakobson 198I: 75I).

I4. Seguint el deixant de Jakobson —i la distinció entre el terme marcat i el terme no marcat de les oposicions fonològiques o gramaticals ( $c f$. un resum a Jakobson i Waugh 1979: 90-92), concepte avançat per Troubetzkoy (I970: 77)-, Hanson i Kiparsky formulen una distinció entre prosa/vers i lírica/narrativa seguint el mateix criteri (I997: 20). Exposada molt condensadament més avall.

I5. Reynolds (I995: I46-I56) identifica un gènere en l'art verbal dels poetes-cantors tradicionals del poble d'al-Bakātūsh, al nord d'Egipte, que té característiques similars, si no idèntiques, a la ghinnāwwa: el mawwāl, un discurs poètic que expressa emocions que no seria honorable expressar en llenguatge quotidià. Aquesta forma poètica descarrega el parlant de tota responsabilitat pel contingut que hi vehicula. De fet, aquests «planys» adverteixen que hom no s'ha de plànyer, però la seva estructura retòrica evita l'expressió directa del plany personal. Segons l'autor, aquesta retòrica abraça tot el folklore egipci i penetra altres gèneres, fins i tot l'èpica. 
Valriu (2007) fa notar «la permeabilitat entre els diversos gèneres folklòrics, en aquest cas la llegenda i la balada», que cal interpretar en termes d'un gènere mixt on es barregen prosa i vers. La seva explicació del fenomen es basa en la distinció entre competència i actuació de la informadora i en el context d'arreplega del material folklòric sota la inducció de l'investigador. Sigui com sigui, reconeix la «competència múltiple» de la informadora i la seva "percepció bàsica dels gèneres folklòrics». Ara, Valriu es refereix a «dues tradicions llegendàries» que «es combinen». De manera que el gènere mixt deriva del coneixement incomplet o circumstancial de la narradora/recitadora de dues tradicions definides, la «llegenda» i la balada — a la manera com solia entendre's el canvi de codi en la recerca sociolingüística: mixtura de dos codis preexistents, identificables i ben definits. Hom ha fet notar posteriorment que aquesta concepció reflecteix més la de l'analista que la dels participants en la interacció comunicativa, els quals devien fer ús dels recursos verbals a llur disposició per crear i negociar un codi emergent, construït amb material de procedència diversa i orientat a assolir una posició d'avantatge en la interacció. No crec que en termes generals la recerca folklòrica -almenys en el cas de gèneres ben establerts i relativament fixats - admeti un paral-lelisme absolut amb aquesta segona concepció del canvi de codi, si bé goso creure que glosadors mallorquins i bertsolaris bascos no se n'allunyen. En tot cas, sí que parteix d'un supòsit paral-lel al de la noció inicial. És possible que la interpretació de Valriu sigui la més adequada en relació amb el material mallorquí que estudia i amb les circumstàncies en què fou aplegat, però aquella «permeabilitat» de gèneres denota no solament un fet propi de l'art verbal, sinó un fet que admet una tipologia complexa. I en part d'això ens ocuparem ací.

\section{Motius d'arreu i la necessitat d'una anàlisi sociocultural i èmica de les produccions de l'art verbal}

Si alguna cosa posen de manifest els estudis aplegats per Harris i Reichl és la necessitat d'interpretar aquest fenomen en termes èmics i històrics, és a dir, com un fenomen que emergeix en tradicions històriques específiques i de comunitats culturals determinades, la interpretació del qual cal cercar en el sentit que li assigna cada comunitat cultural en contextos d'actuació intraculturalment definits. Això és el que també fa palès la versió beduïna a què ens referim. Fins i tot aparents variacions formals i funcionals de la composició, en relació amb les europees vistes suara, han d'interpretar-se en termes èmics. L'inici de la narració en presenta el tema general: ${ }^{16}$

Vet-ací que una vegada hi havia un noi i una noia que estaven enamorats l'un de l'altra.

El fill del germà del pare de la noia se'n va assabentar i s'enrabià. Jurà que la noia mai no es casaria amb el noi i la reclamà per a si.

En aquest cas és un cosí qui ocupa la mateixa funció que pare, mare o marit en els textos esmentats més amunt. Aquesta particularitat s'explica pel paper rellevant que ocupa el vincle entre cosins en una societat patrilineal, en la qual els

I6. La versió catalana de l'annex 5 i, doncs, dels fragments esmentats en el text és de l'autor d'aquest article. 
lligams de sang basats en el llinatge del pare predominen sobre els del llinatge de la mare. Les relacions agnàtiques són extraordinàriament pertinents i en deriven drets i deures dels individus com a membres d'una tribu la pertinença a la qual els identifica. No solament la identitat és en joc, sinó la reproducció de la ideologia dominant i dels patrons culturals del grup. Aquest fet no exclou, tanmateix, la importància dels llaços maternals i de residència comuna, sempre subordinats al llinatge patern. Ara, l'esposori patrilateral entre cosins carnals difumina i fa confluir els lligams per línia paterna i materna. ${ }^{17}$ D'aquí neix la masakhā o dret preferent de l'home a esposar la seva cosina. Aquest és l'origen del sentiment de greuge del «fill del germà del pare de la noia» —és a dir, particularment del cosí germà per via paterna- i la reclamació de la noia «per a si mateix» és la defensa del seu dret.

La narració conté molts dels motius que també apareixen en les balades peninsulars i d'altres que se n'aparten. Així, la mort del noi i la de la noia es produeixen en moments diferents i arran d'episodis diferents. És el cosí qui occeix la noia després que aquesta ha gosat anar al camp del llinatge del seu estimat a plorar-ne la mort, produïda per causa natural, i no és fins que l'ha colpejada fins a la mort que apareix la primera referència comuna: la juxtaposició entre els amants després de morts:

Ella es desplomà ben bé al costat de la tomba ben nova del seu amor.

Malgrat que el cosí ordena que la noia sigui enterrada lluny del seu estimat, no pot evitar que s'esdevingui allò que narra el motiu essencial de l'entrellaçament de branques:

Al cap de poc, nasqué una palmera del cap de la tomba del noi, i un arbre nasqué del cap de la tomba de la noia. Els arbres creixeren i creixeren fins que llurs ramatges s'encreuaren al cel.

Igualment apareix el reconeixement que els amants no se separen ni un cop morts i l'enveja o l'enuig que això provoca en aquells qui han ordenat la destrucció del lligam:

El cosí fou pres d'ira quan ho veié, tot pensant: «Ella encara no pot separar-se d'ell, ni tan sols morta?» Així que anà a trobar el llenyataire perquè talés els arbres.

Salvant, doncs, les característiques específiques que reflecteixen els valors morals i públics amb què la ideologia local tendeix a mantenir l'ordre social, la narració reprodueix els motius que hem trobat en l'art verbal de cultures que ens són molt més pròximes i que solen expressar en vers motius que són compartits.

I7. Aquesta pràctica endogàmica afavoreix el manteniment dels béns d'un llinatge dins aquest mateix llinatge. D'aquí el manament hebreu establert per Moisès que les filles es casin amb els fills dels germans del pare (Nombres 36). Individus i propietats queden vinculats a la tribu. L'acompliment d'aquest principi —i de la seva extensió a altres membres del llinatge- és el tema central del llibre de Rut. 


\section{L'anàlisi poètica i l'especificitat del gènere mixt (prosimetrum) en el context cultural aràbic o d'influència aràbiga}

Hom sol convenir que el vers és el gènere líric per excel-lència, que s'associa d'antuvi amb la primera persona i, doncs, expressa l'emotivitat del subjecte parlant (Jakobson I960, Hanson i Kiparsky I997). Òbviament existeix una literatura èpica en vers, oral o literària — associada a la tercera persona i, per tant, a la narració-, en pobles i cultures d'arreu, des de la llegenda sumèria de Gilgameix i els poemes homèrics fins a l'èpica medieval romànica, i encara fins a Verdaguer, passant pel renaixentista Ariosto o el barroc Milton i el poema «romàntic» Kalevala, refós per Elias Lönnrot. D’aquí que Hanson i Kiparsky (I997: 2O-2I) entenguin la lírica com el gènere no marcat del vers i la narrativa com el gènere marcat, mentre que el gènere no marcat de la prosa seria la narració i el marcat la lírica. Un corol-lari d'això és que, per bé que les funcions de tots dos gèneres siguin variables segons les tradicions i els textos, «el que seria inaudit és que una tradició o un text en què la prosa fos emprada per a les funcions líriques, però no per a les narratives, o en què els vers fos emprat per a les funcions narratives, però no també per a les líriques o en què vers i prosa fossin intercanviables en totes dues funcions» (Hanson i Kiparsky I997: 389).

Probablement aquesta idea bàsica és subjacent al que s'ha escrit sobre la funció del vers en el prosimetrum. En efecte, és habitual considerar que el vers intercalat en una narració en prosa serveix a la reproducció de citacions literals i personals dels herois i a l'expressió del sentiment i l'emotivitat, a l'expressió de lamentacions, malediccions, màgia o eixarms (Bauman 2004), a la moral de la història i altres de semblants. Aquest seria el cas habitual del que Hanson i Kiparsky anomenen provisòriament versiprosa, mentre que en el cas del prosimetrum, en aquest sentit restringit, el vers acompliria funcions com ara la de fer avançar la narració o recapitular-la (Dronke I994: 76, en relació amb Aucassin et Nicolette).

El prosimetrum, en un sentit inclusiu, és una forma narrativa habitual en les cultures de l'Orient Mitjà — sia en rondalles, sia en l'èpica (Reynolds I989)—, tant semítiques com indoeuropees (persa), i, de fet, s'ha pretès que l'aparició del gènere en les literatures grega i llatina és deguda a la influència oriental, opinió que també ha estat contestada o, si més no, matisada. D'una banda, el prosimetrum grecollatí podria ser un desenvolupament intern. De l'altra, en les literatures orientals no existeix una línia divisòria nítida prosa/vers i podria ser que la concepció del prosimetrum no fos la resposta correcta al problema, ateses les dades, sinó la resposta a un plantejament incorrecte del problema a partir de categories occidentals transposades a un món on la relació prosa/vers és més complexa que no sembla (Weitzman I997).

Sigui com vulgui, la narració gravada per Abu-Lughod en àrab dialectal és un clar exemple de la mena de "gènere mixt» que considerem aquí i que, de fet, era clarament predominant en la literatura aràbiga premoderna (Reynolds I997).

Un dels fets que crida l'atenció en aquesta narració és l'absència quasi absoluta de la part dialogada present en els textos romànics peninsulars que hem vist, relativa a: $i$ ) la percepció del cant de l'estimat i el malentès dels pares (galaicoportuguès, castellà) o del nou espòs (català); ii) el reconeixement i declaració de l'estimada, i iii) la irada i cruel reacció paterna o marital. El text anglès tampoc no segueix aquest patró, però hi ha també diàleg. En la narració beduïna, en canvi, 
expressions de forta càrrega emotiva com «Fins i tot morta ets una bagassa!» $\mathrm{O}$ «Ella encara no pot separar-se d'ell, ni tan sols morta?», posades en boca del cosí venjatiu formen part de la narració. Els fragments en vers apareixen solament en boca de l'estimat, en dues ocasions: en el comiat de l'estimada quan ell parteix cap a l'oasi de Siwa i en l'aparició en somnis al llenyataire que ha abatut els arbres per ordre del cosí.

Es tracta d'actes de parla amb valor performatiu. El primer fragment és un comiat en el qual s'expressa el dolor de la separació i la «traïció» que seria la «felicitat» de l'estimada durant l'absència de l'estimat:

Ta felicitat en ma absència és defallença

i el nostre patiment, senyal d'amor...

El segon fragment versificat, pronunciat per l'estimat en una visió que el llenyataire té en somnis és clarament una maledicció i un càstig per causa d'una «metafòrica» $\mathrm{O}$ «proverbial» malifeta:

Tant de bo Déu t'abati, oh llenyataire,

segares la corda mentre pouaven...

El tercer i darrer fragment versificat, que clou la narració, n'és la moral i és una asserció de la força de l'amor i la necessitat del seu acompliment:

\section{L'amor ha de donar fruits}

els quals s'uneixen al cel l'un amb l'altre.

És evident que la funció dels versos en aquesta narració és l'expressió de forts sentiments d'afectivitat: l'enyorança, la maledicció i la moral, expressió de la força de l'amor.

En la societat tradicional aràbiga, la poesia era un gènere investit d'autoritat i de veritat. En part per la seva vinculació amb la tradició oral preislàmica i, doncs, amb la seva capacitat de permanència al llarg del temps — primordialment en poemes èpics o relació de gestes. ${ }^{18}$

Reynolds (I997: 278-279) distingeix cinc funcions de la poesia aràbiga premoderna i, d'aquestes, tres s'adiuen al nostre context: l'esmentada expressió dels sentiments íntims com a forma — a contrario - de manifestar el control públic de les emocions; la força de la persuasió, i l'expressió de la bellesa, en un grau molt superior a la prosa, inclús a la prosa rimada.

En la seva ressenya dels gèneres mixtos en obres escrites de la literatura persa medieval, fossin redactades en aquesta llengua o ho fossin en àrab, Scott Meisami (I997: 292), si bé hi fa èmfasi en la quasi indiferenciació de prosa i vers, remarca que no s'ha de menystenir la dimensió oral d'aquestes obres, no pas quant a la composició, sinó en «l'oralitat residual» que les connecta amb els gèneres orals i llur «performance» i en els quals la distinció entre prosa i vers identificava clarament dos registres (Kalila i Dimna en seria una mostra).

I8. «La poesia és l'arxiu dels àrabs» (Heinrichs 1997: 249). «Els àrabs, en llur Temps de la Ignorància [abans de l'Islam], solien esmerçar-se per immortalitzar-los [llurs fets gloriosos] confiant-los a la poesia, que és un discurs mètric i rimat, i aquest era llur arxiu (dīwān)» (Al-Jāhiz, escriptor del segle IX, Hayawān, I: 7I-72, apud Heinrichs I997: 25I). Aquí ens interessa destacar, amb tota reserva atès el gènere, aquest valor de veritat, de certificació dels fets, que implica la poesia i que ve del seu temps immemorial, dels orígens preislàmics. 


\section{Algunes consideracions sobre altres propostes de gènere mixt i la}

\section{transposició de gèneres}

Diego Catalán (I970) en el seu estudi sobre les versions del romanç «Enamorada de un muerto» — del qual remarca l'extrema difusió en català (I970: I93) i al qual dedica unes quantes pàgines - anomena romance mixto la confluència de dos romanços en un de sol o la interpolació d'un romanç dins un altre romanç, concretament als romanços «Enamorada de un muerto» $i$ «Conde Nilo», versions «mixtes» recollides sobretot al Pirineu aragonès i altres zones de l'Aragó, i presents també en altres llocs de la Península. ${ }^{19}$ No cal dir que no es tracta d'un gènere mixt o que, en tot cas, la mixtura no és de gèneres, sinó que el terme «mixt» hi designa una cosa ben diferent del prosimetrum.

Més interessant, en canvi, és el fenomen de la transposició de gèneres —il-lustrat per Oriol (2007)—, en què existeixen, per exemple, versions d'un mateix argument en romanç, rondalla o llegenda, les quals són activades en funció del «repertori temàtic» del narrador i de la circumstància de l'actuació (Oriol 2007: II). Com indica l'autora, aquí l'element constant és el contingut i el variable la forma ${ }^{2 \circ}$ («prosificació» del romanç) —i també una gradació d'interactivitat. Exemple d'aquesta última el donen els textos analitzats per l'autora: del romanç a la rondalla, i del romanç al poema literari ${ }^{21}$ - i entremig podríem afegir-hi la creació/fabricació textual del recol-lector de romanços o rondalles, sovint no pas poc irrellevant: són conegudes certes pràctiques metadiscursives de descontextualització i de (re)elaboració i «purificació» que aquells pateixen de mans dels folkloristes, malgrat llur voluntat declarada d'atenir-se a l'«autenticitat».22 El cas és també una mostra de la permeabilitat genèrica esmentada per Valriu, però d'una naturalesa altra que la del gènere mixt:

El romanç «L'Escriveta» ha traspassat les fronteres del seu propi gènere, ja que s'ha adaptat a les característiques formals i estilístiques d'una rondalla i d'un poema. [...] Aquestes projeccions del romanç [...] tenen a veure

I9. Pel que fa al material català que hi aporta, és ben curiós que no hi faci notar l'alternança de llengües, qüestió que mereixeria un estudi per ella mateixa.

20. Més enllà de la mera variant temàtica o formal del romanç, per exemple.

2I. Es tracta del romanç «L'Escriveta», de la seva conversió en narració i, finalment, de l'elaboració literària que en fa Josep Carner al romanç «La filla del Carmesí». Aquesta escala d'interactivitat fa pensar en la distinció herderiana entre la Naturpoesie i la Kunstpoesie, que n'ocuparien els extrems.

22. Per a una crítica de la «ideologia textual» i de les pràctiques metadiscursives de descontextualització, transcripció i elaboració textual dels germans Grimm, la controvèrsia subsegüent (contemporània i actual), la contribució dels Grimm a la definició de la tradició i la modernitat — o a la deglució de la primera per la segona-, a la construcció de l'auctoritas de «l'especialista», a la invenció del Volks i a la ideologia nacional, vegeu Bauman i Briggs (2003, cap. 6, esp. p. 206-2I6). Podem estendre una semblant visió crítica quant a les pràctiques de descontextualització i retextualització dels nostres folkloristes més conspicus: valgui l'exemple de les Rondaies Mallorquines de mossèn Antoni M. Alcover. En descàrrec, ell no es considerava folklorista, sinó lliurat a una missió "patriòtica», però vegeu l'exposició de criteris que ell mateix dóna quant a una obra que pretén preservar el patrimoni llegat per transmissió oral i alhora és passada pel sedàs d'una tria basada en criteris morals i d'una elaboració literària (Alcover I93I; Moll 2004). 
amb el grau d'interacció que es produeix entre el narrador i el seu públic (Oriol 2007: 24).

La primera part de la citació ens remet a la transposició de gèneres (amb aproximadament un mateix argument). La segona part es refereix a la «distància» —o «proximitat»- interactiva. Referent a això, quan Oriol situa la narració aplegada - la «rondalla»— entre la forma «pròxima» del romanç i la forma distant de l'elaboració literària, fa la impressió que barreja dues perspectives diferents: una, la interactivista; l'altra, la genètico-textual. Si considerem la narració com una "prosificació» del romanç és evident que aquest, en tant que «text», ha de precedir genèticament la rondalla. Ara, des d'un punt de vista interactiu - al qual dóna raonablement preeminència l'autora, com a investigadora implicada en una perspectiva vinculada d'antuvi a la «performance» abans que al «text»—, la narració aportada és molt rica d'anotacions al marge, de comentaris metadiscursius i d'atribucions de la narració original a d'altri, fetes per la narradora. Totes tres coses són característiques d'un acte de «performance» —això, havent-se perdut en la transcripció eventuals veus estrafetes o altres estratègies de la narració oral- i, encara que no sembla que hi hagi l'expectativa d'una participació activa de l'audiència en l'ocasió comunicativa concreta, els recursos emprats per la narradora pressuposen l'interlocutor i s'hi adrecen particularment, alhora que narració i narradora estan subjectes a avaluació — característica crucial de la "performance», com ho és la consciència (o la «competència» a què es referia Valriu) metadiscursiva de la narradora. ${ }^{23} \mathrm{Al}$ nostre parer, la narració reportada — no necessàriament la rondalla com a gènere textual - té un caràcter més interactiu que la «performance» d'un romanç. Si anem ben encaminats, doncs, cal reconèixer que l'ordre dels gèneres en l'escala d'interactivitat («proximitat»/«distància») i l'ordre dels gèneres en la dimensió genètica difereixen.

\section{Breu recapitulació}

A manera de resum, hem vist com cultures peninsulars i europees comparteixen el motiu de les «branques entrellaçades» (E63I.o.I), totes servint-se d'una forma textual comuna en la mesura que apareix en textos versificats: el romanç romànic i la balada en llengua anglesa als EUA, rebuda d'Europa. Els elements contextuals difereixen d'un cas a un altre, però el motiu E63I.o.I els dóna unitat. No hem sabut trobar el motiu en el romancer català, però sí la «versió ornitològica», copresent amb E63I.O.I en els casos galaicoportuguès i castellà. En canvi, Amades la recull en una narració i fa pensar que el narrador la devia haver oït de versions versificades. Hem retrobat el motiu en una narració d'una tradició beduïna del desert Líbic, amb una forma textual ben diversa, en tractar-se d'un «gènere mixt» de prosa i vers (prosimetrum —en la versió que alguns anomenarien «versiprosa»-). Hem notat com certes diferències en l'anàlisi formal i funcional del text el vinculen a una determinada societat amb uns patrons culturals i ideològics específics $i$ ben diversos dels casos anteriors i, en fi, hem aportat una interpretació del sentit

23. Aquest fet es fa evident almenys en dos punts de la narració: «Bueno, ella ho explicava molt, amb aquestes paraules d'abans, saps?, amb aquells adagis i tot això» i «Llavons ho deien així, tot era en prosa, i a mi m'encantava escoltar-ho» (Oriol I997: I5 i I6, respectivament). Com nota l'autora, en la segona acotació, hi ha un lapsus: «prosa» per «poesia» - però la consciència de la diferència formal hi és. 
del gènere mixt i dels fragments versificats en termes de diverses tradicions orientals i, específicament, de la tradició aràbiga premoderna. Solament una aproximació èmica a l'estudi d'aquests textos en els respectius contextos culturals ens en permet treure l'entrellat i la significació que cal atorgar-los, entesa com a resultat de la interacció simbòlica conjunta d'uns actors — narrador i audiència- en un context sociocultural i en un context de situació concrets, és a dir, com un constructe cultural vinculat a un context.

Tangencialment, hem tractat d'eventuals fenòmens de simbiosi lírica o narrativa, però que no es poden considerar un gènere mixt, i del fenomen de la transposició de gèneres, com a mostra de permeabilitat genèrica, però no de gènere mixt, i de la interpretació de les relacions de genètica textual i de gradació interactiva que generen.

\section{Referències bibliogràfiques i discogràfiques}

ABU-LUGHOD, Lila (I986): Veiled sentiments: Honor and poetry in a Bedouin society. Berkeley / Los Angeles: University of California Press.

Alcover, Antoni M. (I93I): «Com he fet mon Aplec de Rondaies Mallorquines». Zeitschrift für Romanische Philologie, p. 94-III.

Amades, Joan (I950): Folklore de Catalunya. Rondallística (Rondalles-TradicionsLlegendes). Biblioteca Perenne i3. Barcelona: Editorial Selecta.

ANDRADE, Eugénio de (I999): Antologia pessoal de poesia portuguesa. Porto: Campo das Letras.

BAUMAN, Richard (2004): “'And the verse is thus': Icelandic stories about magical poems». Dins A World of Others' Words. Oxford: Blackwell, p. II-33.

BAUMAN, Richard; Charles L. BRIGgS (2003): Voices of modernity. Language ideologies and the politics of inequality. Cambridge: Cambridge University Press.

BoHIgAs, Pere (I983 [I938]): Cançoner popular català. Biblioteca Serra d'Or. Barcelona: Publicacions de l'Abadia de Montserrat, 2 vols.

CATAlán, Diego (I970): Por caminos del romancero. Estudios sobre la tradición oral moderna. Biblioteca Románica Hispánica II. Estudios y Ensayos I42. Madrid: Gredos.

CHILD, Francis James (selecció i edició de) (1857): English and Scottish Ballads. Boston: Little, Brown and Company.

DRONKE, Peter (I994): Verse with prose from Petronius to Dante: The art and scope of the mixed form. Cambridge/London: Harvard University Press.

GARfunkel, Art (I973): «Barbara Allen». Dins Angel Clare. Washington DC: Columbia Records.

HANSON, Kristin; Paul KIPARSKY (I997): «The nature of verse and its consequence for the mixed form». Dins Joseph HARris; Karl REICHL (eds.) (I997), p. I7-44.

HARRIS, Joseph; Karl ReICHL (eds.) (I997): Prosimetrum. Cross-cultural perspectives on narrative in prose and verse. Cambridge: D. S. Brewer.

HAUf, Albert (20IO): «Les transformacions». Dins Temes mallorquins. Barcelona: Publicacions de l'Abadia de Montserrat, p. 3I3-348. 
«Les branques entrellaçades»: un motiu del folklore verbal i els gèneres mixtos

HEINRICHS, Wolfhart (I997): «Prosimetrical genres in classical Arabic literature». Dins Joseph HARRIS; Karl REICHL (eds.) (I997), p. 249-275.

Ismael (I963): «Conde Niño». Canciones Del Pueblo - Canciones Del Rey. París: BAM - LD 406.

JAKOBSON, Roman (I98I [I935]): «The dominant». Dins Selected Writings, vol. 3. The Hague: Mouton, p. 75I-756.

JaKobSON, Roman (I960): «Linguistics and poetics». Dins Thomas A. SebeOK (eds.): Style in language. Cambridge, Mass.: The MIT Press, p. 350-377.

JAKOBSON, Roman; Linda WAUGH (I979): The sound shape of language. Brighton: The Harvester Press.

MENÉNDEZ PIDAL, Ramón (I948 [I928]): Flor nueva de romances viejos. Colección Austral Ioo. Madrid: Espasa Calpe, 7a ed.

Moll, Francesc de B. (2004 [I970]): «La censura moral de Mossèn Alcover a les seves Rondaies Mallorquines». Dins Obres completes II, p. I99-207.

ORIOL, Carme (2007): «El romanç “L'Escriveta” en el folklore i en la literatura». Dins Jaume GUISCAFRÈ; Caterina VALRIU (eds.): La poesia oral: gèneres, funcionalitat i pervivència. Palma/Barcelona: Universitat de les Illes Balears / Publicacions de l'Abadia de Montserrat, p. 9-25.

OrIOL, Carme; Josep M. PUJOL (2003): Índex tipològic de la rondalla catalana. Materials d'etnologia de Catalunya 2. Barcelona: Generalitat de Catalunya, Departament de Cultura.

Ovidi (I930): Les metamorfosis. Text revisat i traducció d'Adela M. TREPAT; Anna M. de SAAVEDRA. Barcelona: Fundació Bernat Metge, vol. 2.

Ovidi (I996): Les metamorfosis. Presentació i traducció de Jordi PARRAMON. Barcelona: Quaderns Crema.

PAlOMA, J. A. (curador) (I980): Romancer Català, text establert per Manuel Milà I FonTANALS. MOLC 47. Barcelona: Edicions 62 / La Caixa.

REYNOLDS, Dwight (I989): «Sīrat Banī Hilāl: Introduction and Notes to an Arab Oral Epic Tradition». Oral Tradition 4: 80-Ioo.

REYNOLDS, Dwight (I995): Heroic poets, poetic heroes. Ithaca/Londres: Cornell University Press.

REYNOLDS, Dwight (I997): «Prosimetrum in Nineteenth- and Twentieth-Century Arabic literature». Dins Joseph HARRIs; Karl ReICHL (eds.) (I997), p. 277-294.

SEeger, Pete (2003 [I958]): «Barbara Allen». Dins American favorite ballads, Nova York: Folkways Recordings, vol. 2 [Washington DC: Smithsonian Folkways. Smithsonian Center for Folklife and Cultural Heritage].

THOMPSON, Stith (I966): Motif-index of folk-literature; a classification of narrative in folktales, ballads, myths, fables, medieval romances, exemple, flabiaux, jest-books and local legends. Bloomington: Indiana University Press.

Troubetzkoy, N. S. (I97o [I939]): Principes de phonologie. París: Klincksieck.

UTHER, Hans-Jörg (2004): The Types of International Folktales. Folklore Fellows' Communications 284, 285, 286. Hèlsinki: Suomalainen Tiedeakatemia. 
VALRIU LLINÀS, Caterina (2007): «Imbricacions entre la llegenda i la balada: el cas del comte Mal». Dins Caterina VAlriu; Joan Armangué (eds.): Els gèneres etnopoètics. Competència i actuació. Dolianova: Grafica del Parteolla [Arxiu de Tradicions de l'Alguer], p. I67-I75.

WeitzMan, Steven (I997): «The 'Orientalization' of prosimetrum: Prosimetrum in Biblical and ancient Near Eastern literature». Dins Joseph HARRIs; Karl REICHL (eds.) (I997), p. 225-247.

\section{Annexos}

\subsection{Conde Nilo}

Conde Nilo, conde Nilo

Seu cavalo vai banhar;

Enquanto o cavalo bebe,

Armou un lindo cantar.

Com o escuro que fazia

El-rei nâo o pode avistar.

Mal sabe a pobre da infanta

Se há-de rir, se há-de chorar.

- «Cala, minha filha, escuta,

Ouvirás un bel cantar:

Ou sâo os anjos no Céu,

Ou a sereia no mar.»

- «Nâo sâo os anjos no Céu,

Nem a sereia no mar:

É o conde Nilo, meu pai,

Que comigo quer casar.»

- «Quem fala no conde Nilo,

Quem se atreve a nomear

Esse vassalo rebelde

Que eu mandei desterrar?»

- «Senhor, a culpa é só minha,

A mim deveis castigar:

Nâo posso vivir sem ele...

Fui eu que o mandei chamar.»

- «Cala-te, filha traidora,

Nâo te queiras desonrar.

Antes que o dia amanheça

Vê-lo-ás ir a degolar.» 
«Les branques entrellaçades»: un motiu del folklore verbal i els gèneres mixtos

- «Algoz que o matar a ele,

A mim me tem de matar;

A donde a cova lhe abrirem,

A mim me tem d'enterrar.»

Por quem dobra aquela campa,

Por quem está a dobrar?

- «Mort é o conde Nilo,

A infanta já a expirar.

Abertas estâo as covas,

Agora os vâo a enterrar:

Ele no adro da igreja,

A infanta ao pé do altar.»

De um nascera um cipreste,

E do outro um laranjal,

Um crescia, outro crescia,

Coas pontas se iam beijar.

El-rei, apenas tal soube,

Logo os mandara cortar.

Um deitava sangue vivo,

O outro sangue real;

De um nascera uma pomba,

De outro um pombo torcaz.

Senta-se el-rei a comer,

Na mesa lhe iam poisar:

- «Mal haja tanto querer,

E mal haja tanto amar!

Nem na vida nem na morte

Nunca os pude separar.»

Eugénio de ANDRADE (I999): «Conde Nilo». Dins Antologia pessoal de poesia portuguesa. Porto: Campo das Letras, p. 53-55. 
Joan A. Argenter i Giralt

\subsection{Romance del Conde Niño}

Conde Niño, por amores

es niño y pasó la mar;

va a dar agua a su caballo

la mañana de San Juan.

Mientras el caballo bebe

él canta dulce cantar;

todas las aves del cielo

se paraban a escuchar;

caminante que camina

olvida su caminar,

navegante que navega

la nave vuelve hacia allá.

La reina estaba labrando,

la hija durmiendo está:

-Levantaos, Albaniña, de vuestro dulce folgar, sentiréis cantar hermoso

la sirenita del mar.

-No es la sirenita, madre, la de tan bello cantar, si no es el Conde Niño que por mí quiere finar. ¡Quién le pudiese valer en su tan triste penar! - Si por tus amores pena, ¡oh, malhaya su cantar!, y porque nunca los goce yo le mandaré matar.

- Si le manda matar, madre juntos nos han de enterrar. Él murió a la media noche, ella a los gallos cantar; a ella como hija de reyes la entierran en el altar, a él como hijo de conde unos pasos más atrás.

De ella nació un rosal blanco, 
«Les branques entrellaçades»: un motiu del folklore verbal i els gèneres mixtos

de él nació un espino albar;

crece el uno, crece el otro,

los dos se van a juntar;

las ramitas que se alcanzan

fuertes abrazos se dan,

y las que no se alcanzaban

no dejan de suspirar.

La reina, llena de envidia,

ambos los mandó cortar;

el galán que los cortaba

no cesaba de llorar;

della naciera una garza,

dél un fuerte gavilán

juntos vuelan por el cielo,

juntos vuelan a la par.

Ramón Menéndez PidAl (I948): «Romance del Conde Niño». Dins Flor nueva de romances viejos. Colección Austral ıoo. Madrid: Espasa Calpe, 7a ed., p. I3O-I3I.

\subsection{Don Lluís de Montalbà}

La vida de la galera

amor, bé m'esperareu

Demano llicència al comte

me’n dóna per penitència

De tant content que hi anava

Me'n vaig a casa la tia

«Déu lo guard, la meva tia,

«Aquell que me'n deia, tia,

«No va per galeres, tia,

«Me'n diria, la meva tia,

«La teva mare, don Lluís,

«Me'n diria, la meva tia,

«Lo teu pare, don Lluís,

«Me'n diria, la meva tia,

«Lo teu germà, don Lluís, n'és molt llarga de contar

fins que hauré fet los set anys

i el comte me la vol dar;

amb tres hores passar el mar.

hora i mitja hi vaig posar;

la tia de Montalbà:

la meva tia, com va?»

set anys per galeres va.»

que a vostre costat n'està.

la meva mare què fa?»

soterrada n'és temps ha.»

i lo meu pare què fa?»

ja n'és cego de plorar.»

i lo meu germà què fa?»

pres de moros n'és temps ha.» 
«Me'n diria, la meva tia,

«Don Lluís, la teva esposa

esta nit se'n fan les cartes

«Me'n diria, la meva tia,

«Carrer de Santa Maria

«Tia, baixeu-me el sombrero,

I baixeu-me la guitarra,

Lo primer cant que li feia

«Desperteu-vos, vida mia,

sentireu cant de serena

«Això no és cant de serena

sinó que és lo meu marit

«Si és veritat, vida mia,

«Si mateu lo meu marit

La un mor a mitja nit,

l'altar de Santa Maria

de l'un surt una coloma la meva esposa què fa?»

està en tractes de casar;

si no és anit serà demà.»

ane quin carrer n'està?»

al portal més prop del mar.»

lo que em solia posar

la que solia tocar.»

son marit se despertà:

si voleu sentir cantar,

o peix que roda pel mar.»

o peix que roda pel mar,

lo que me vàreu quitar.»

prompte l'aniré a matar.»

per mi podeu començar.»

l'altre al despuntar el clar,

los dos varen enterrar;

i de l'altre un colomar.

«Don Lluís de Montalbà». Dins J. A. Paloma (curador) (I980): Romancer Català, text establert per Manuel Milà i FontAnAls. MOLC 47. Barcelona: Edicions 62/la Caixa, p. 87.

\subsection{Balada de Barbara Allen}

All in the merry month of May,

When green buds all are swellin'.

Sweet William on his deathbed lay for love of Barbara Allen.

He sent his servant to the town,

The place where she did dwell in.

Saying, "Master dear has sent me here if your name be Barbara Allen."

Then slowly, slowly she got up and slowly she went to him,

And all she said when there she came was, "Young man, I think you're dying.

"Don't you remember the other night when we were in the tavern?

You drank a toast to the ladies there and slighted Barbara Allen."

He turned his face unto the wall,

He turned his back upon her. 
«Les branques entrellaçades»: un motiu del folklore verbal i els gèneres mixtos

"Adieu, adieu, to all my friends.

And be kind, be kind to Barbara Allen."

As she was wandering on the fields she heard the death bell knellin'.

And every note, it seemed to say,

"Hard-hearted Barbara Allen!"

The more it tolled the more she grieved,

She bursted out a-crying.

"Oh, pick me up and carry me home.

I fear that I am dying."

They buried Willy in the old church yard and Barbara in the new one, And from William's grave, there grew a rose, from Barbara's, a green briar. They grew and grew in the old church yard,

Till they could grow no higher,

And there they tied in a true lover's knot,

The red rose and the briar.

Art Garfunkel (I973): «Barbara Allen». Dins Angel Clare. Washington DC: Columbia Records.

\subsection{Conte beduí (Awlad 'Ali) ${ }^{24}$}

Vet-ací que una vegada hi havia un noi i una noia que estaven enamorats l'un de l'altra.

El fill del germà del pare de la noia se'n va assabentar i s'enrabià. Jurà que la noia mai no es casaria amb el noi i la reclamà per a si.

La noia i el noi solien trobar-se en secret per conversar a la tenda d'una vella dama, veïna d'ells. Un bon dia el noi anuncià que havia de partir de viatge. Se n'anava a l'oasi de Siwa a arreplegar dàtils. Prometé que tan bon punt tornés es casaria amb la noia. Li digué:

Ta felicitat en ma absència és defallença

i el nostre patiment, senyal d'amor...

zahā fī ghiyābī nagṣ

wil-ḥizn bēnnā mārat ghalā...

Així, doncs, ell es posà en marxa amb una caravana de camells. Estigué bon temps fora. De tornada, quan faltaven solament dos dies de camí per arribar a casa, emmalaltí i morí. Abans havia donat instruccions al seu company: «Si moro pel camí, si us plau dugueu el meu cos a casa, de manera que la meva família em

24. Atesa la dificultat de transcriure i transliterar l'àrab dialectal, mantenim la transcripció de l'autora tal com apareix a Abu-Lughod (1986). Agraeixo a Lluís Polanco les entenimentades reserves amb què ha considerat el problema d'una eventual retransliteració i a Lila Abu-Lughod la confirmació del problema ja en origen. 
pugui sebollir». El seu company, doncs, carregà el cadàver a camell i féu camí fins arribar a casa.

Quan la família del noi s'assabentà del que havia passat, rompé en plors i laments. Mentrestant, la noia havia vist arribar els camells al campament del noi, però es preguntà: «Per què no sento els cants de joia i el foc dels rifles [signes de celebració]?» Corregué a esbrinar-ho i quan ho hagué fet, rompé en plors i laments amb les dones del llinatge.

El seu cosí descobrí que ella havia anat al campament del seu estimat i la seguí. Corregué i l'arrabassà d'entre les ploraneres i començà a colpejar-la. Ella mirà de fugir, però ell l'empaità i l'atrapà, i la colpejà fins a la mort. Ella es desplomà ben bé al costat de la tomba tot nova del seu amor.

El seu cosí s'enrabià. L'insultà: «Fins i tot morta ets una bagassa!». Demanà que no l'enterressin prop del noi, de manera que se l'endugueren, si fa no fa, un quilòmetre més lluny i l'enterraren.

Al cap de poc, nasqué una palmera del cap de la tomba del noi, i un arbre nasqué del cap de la tomba de la noia. Els arbres creixeren i creixeren fins que llurs ramatges s'encreuaren al cel. El cosí fou pres d'ira quan ho veié, tot pensant «Ella encara no pot separar-se d'ell, ni tan sols morta?». Així que anà a trobar el llenyataire perquè talés els arbres.

Quan el llenyataire intentava abatre l'arbre que creixia sobre la tomba de la noia, tot d'una la destral li fugí de les mans i li anà a parar a l'ull: el deixà cec. Tornà a casa i caigué malalt. En somnis tingué una visió: el noi se li acostà i li digué:

Tant de bo Déu t'abati, oh llenyataire,

segares la corda mentre pouaven...

allah yigta'ak yā najjār

gāți‘ dlī fì mlāhum...

Després se'n tornà amb aquests mots:

L'amor ha de donar fruits

els quals s'uneixen al cel l'un amb l'altre

1-asbid min ghalā ynabbit athmār

yit'ālagun fì smāhum...

Lila ABU-LUgHOD (I986): Veiled sentiments: Honor and poetry in a Bedouin society. Berkeley/Los Angeles: University of California Press, p. 249-250. 